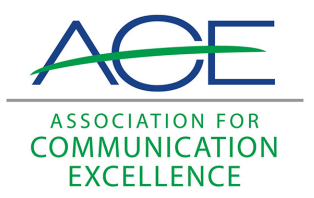

Journal of Applied Communications

Volume 100

\title{
Coming of Age: How JAC is Reflecting a National Research Agenda for Communications in Agriculture, Natural Resources, and Life Human Sciences
}

Lulu Rodriguez

James F. Evans

Follow this and additional works at: https://newprairiepress.org/jac

cc) (†)

This work is licensed under a Creative Commons Attribution-Noncommercial-Share Alike 3.0 License.

\section{Recommended Citation}

Rodriguez, Lulu and Evans, James F. (2016) "Coming of Age: How JAC is Reflecting a National Research Agenda for Communications in Agriculture, Natural Resources, and Life Human Sciences," Journal of Applied Communications: Vol. 100: Iss. 1. https://doi.org/10.4148/1051-0834.1020

This Research is brought to you for free and open access by New Prairie Press. It has been accepted for inclusion in Journal of Applied Communications by an authorized administrator of New Prairie Press. For more information, please contact cads@k-state.edu. 


\title{
Coming of Age: How JAC is Reflecting a National Research Agenda for Communications in Agriculture, Natural Resources, and Life Human Sciences
}

\author{
Abstract \\ This study analyzed communications research trends, topics, needs, and opportunities involving \\ agriculture, natural resources, and life and human sciences since the development of a national research \\ agenda (NRA) in 2007. A content analysis of 23 issues of the Journal of Applied Communications (JAC) \\ published over 7.5 years (2008 to mid-2015) examined the degree to which the articles reflected the \\ priority research areas (PRAs), key research questions (KRQs), and priority initiatives (PIs) identified in the \\ NRA. Findings showed a watershed period from 2011-2014 in which the journal produced an average of \\ 18 articles per year. The first RPA (RPA A), "Enhancing decision making within the agricultural sectors of \\ society," received the most attention, followed by RPA B, which focused on rural-urban interactions. Within \\ RPA A, the largest number of articles addressed the key research question, "What are the most effective \\ ways to identify and communicate information that has economic and social value?" Under this question, \\ the priority initiative (PI), "Analyze and strengthen the effectiveness of communications content and \\ methods in communicating information," garnered the most research attention. Findings showed a dearth \\ of studies in PIs across the four RPAs, including economic returns to, and social impacts of, agricultural \\ information; how to engage key interest groups in decision making; models of collaboration, negotiation, \\ and conflict management; use of critical theory in analyzing agriculture and related communications; the \\ interplay between data, information and meaning within stakeholders; information asymmetries and \\ barriers to public participation in decision making; the mechanisms by which information is made \\ available; if and how knowledge gains value; and ethical issues and standards. Results prompted seven \\ suggestions for further research progress and direction.
}

\section{Keywords}

Agricultural Communications, Research Agendas, Research Themes, Research Needs, Journal of Applied Communications 


\section{Coming of Age: How JAC is Reflecting a National Research Agenda for Communications in Agriculture, Natural Resources, and Life and Human Sciences}

\section{Lulu Rodriguez and James F. Evans}

\section{Abstract}

This study analyzed communications research trends, topics, needs, and opportunities involving agriculture, natural resources, and life and human sciences since the development of a national research agenda (NRA) in 2007. A content analysis of 23 issues of the Journal of Applied Communications (JAC) published over 7.5 years (2008 to mid-2015) examined the degree to which the articles reflected the priority research areas (PRAs), key research questions (KRQs), and priority initiatives (PIs) identified in the NRA. Findings showed a watershed period from 2011-2014 in which the journal produced an average of 18 articles per year. The first RPA (RPA A), "Enhancing decision making within the agricultural sectors of society," received the most attention, followed by $R P A B$, which focused on rural-urban interactions. Within $R P A$ $A$, the largest number of articles addressed the key research question, "What are the most effective ways to identify and communicate information that has economic and social value?" Under this question, the priority initiative (PI), "Analyze and strengthen the effectiveness of communications content and methods in communicating information," garnered the most research attention. Findings showed a dearth of studies in PIs across the four RPAs, including economic returns to, and social impacts of, agricultural information; how to engage key interest groups in decision making; models of collaboration, negotiation, and conflict management; use of critical theory in analyzing agriculture and related communications; the interplay between data, information and meaning within stakeholders; information asymmetries and barriers to public participation in decision making; the mechanisms by which information is made available; if and how knowledge gains value; and ethical issues and standards. Results prompted seven suggestions for further research progress and direction.

\section{Key Words}

Agricultural Communications, Research Agendas, Research Themes, Research Needs, Journal of Applied Communications

\section{Literature Review}

Nothing speaks more loudly of an academic discipline's commitment to help address the issues and problems facing individuals, organizations, and communities both locally and abroad than the announcement of its national research agenda (NRA). The NRA proclaims the focus of a discipline and serves as an internal compass to direct collaborative efforts and resources toward a scope of work. It provides a framework for research efforts and for targets, which evolve in the light of current and anticipated challenges (Doerfert, 2011).

The authors acknowledge with appreciation the important support of Shuoying Cui in this research project. 
By setting forth a national research agenda, organizations, groups, or consortia hope to catalyze researchers, policy professionals, and national, state, and local leaders to improve how they respond to the challenges facing the discipline and the society within which it operates. A robust research base enables the furthering of best practices for those working within the discipline and allied fields and is a key element in demonstrating the field's relevance in addressing the needs of local and global societies. An extensive review of published studies and research currently under way as well as key policy areas informs most NRAs.

The research topics proposed in an agenda are typically organized across domains. Taken together, these topics cover the range of issues facing the discipline, seeking to implement solutions that work. In general, NRAs are directed to those who do research, use research, support research, and those who could become involved in research in some capacity. Both funders and researchers are expected to use the agenda to guide their choices about future investments in research within the discipline. The NRA is expected to be an evolving document to be reviewed and updated periodically in response to changing needs, understanding, and opportunities (U.S. Interagency Council on Homelessness, 2012). The goal, in the case of the Agricultural Communications NRA, is to advance the discipline while providing research- and experience-based solutions that address complex human interactions in agriculture, the environment, and natural resources.

\section{Historical Background}

In 2007, results were published from a joint national project to envision a framework and agenda for research in agricultural communications, agricultural leadership, agricultural education, and extension education (Osborne, 2007). The American Association for Agricultural Education (AAAE), Association for Communication Excellence in Agriculture, Natural Resources, and Life and Human Sciences (ACE), the Association for International Agricultural and Extension Education (AIAEE), the Association of Leadership Educators (ALE), NCAC24 of the Experiment Station Committee on Organization and Policy, and the National Council for Agricultural Education released the NRA "to effectively communicate research priorities to numerous state and national interests, including agricultural experiment station directors, USDA program administrators, and funding agencies" (Osborne, 2007, p. 2). To help guide research initiatives, it was featured prominently on the websites of professional societies and organizations that collaborated in developing the document. The NRA identified Research Priority Areas (RPAs), each of which included up to four Key Research Questions (KRQs) or critical research problems. Specific dimensions of each key research question were designated as Priority Initiatives (PIs).

Within the joint project, "agricultural communications" was interpreted broadly to involve communications related to food and nutrition, farming and ranching, natural resources and the environment, renewable energy, natural fibers, rural and community development, rural affairs, and associated activities. A report of the communications framework and agenda was subsequently published in a 2007 JAC article authored by Doerfert, Evans, Cartmell \& Irani.

The NRA in Agricultural Communications was a product of a series of roundtable discussions on the changing conditions in the agricultural communications discipline and professions in the United States and the state of research in ACE member institutions. It incorporated the best thinking of national experts, including institutional leaders, senior researchers, and representatives from organizations that fund research. Although the target audiences were not specified, the NRA directed ACE members to consider what types of research would contribute most to the growth of the discipline, and hence, should be supported.

\section{JAC as Lead Journal}

Since its inaugural issue in 1968 as aaace (Carnahan, 2000), the quarterly Journal of Applied Communications (JAC), ACE's official journal, has been acknowledged as the lead publication 
in reporting about advances in research and practice about communications in the subject areas of food and nutrition, farming and ranching, natural resources and the environment, renewable energy, natural fibers, rural affairs, community development, and related activities. These subject areas represent integral mandates of the U.S. Department of Agriculture and those of colleges and universities of agriculture nationwide. Today, the publication serves as a refereed journal "offering professional development for educational communicators who emphasize agriculture, natural resources, and life and human sciences. It welcomes original contributions from any author, although priority may be given to ACE members, should articles of comparable quality be available” (Journal of Applied Communications, n.d., \1-2). Articles published in the JAC fall under the following four categories: (1) research and evaluation articles, which are traditional scholarly articles that employ quantitative (e.g., statistical and survey methods) and/or qualitative (e.g., case and ethonographic studies) methods; (2) professional development articles, which take advantage of the author's particular expertise on a subject that benefits career performance of ACE members and others; (3) commentaries or opinion pieces that discuss trends in communication or other issues of importance to professional communicators; and (4) reviews, which typically are critiques of new books, journal articles, software/hardware, technologies, or any material that would be appropriate for the JAC audience. Theoretical and applied articles are prioritized based on their direct value to ACE members.

\section{The Study}

The NRA in Agricultural Communications, developed in 2005-2006 and released in 2007, provides a valuable framework for analyzing the research subject matter areas and themes the journal has addressed since then. The current study aimed to synthesize the research themes and domains published in the journal from 2008 to mid-2015.

The NRA lists four priority areas for communications research: (1) enhance decision making within the agriculture sectors of society; (2) within and among societies, help the public take part in decision making related to agriculture; (3) build societal knowledge and intellectual capabilities; and (4) develop effective agricultural workforces for knowledge-based societies.

Eighteen key research questions and 59 priority initiatives fit within those areas. The present study aimed to ascertain the amount and extent of coverage that have been directed toward each priority area, key research question, and priority initiative.

Part of the synthesis also involved surveying the theories applied or tested, the methods used to gather data, and the populations studied, so the results can be considered with those of Williams \& Woods (2002) who offered a synthesis of agricultural communications research published in the JAC from 1992 to 2001, and those of Edgar, Rutherford \& Briers (2009) who analyzed JAC articles published from 1997 through 2006.

The present study offers a comprehensive analysis of research articles published in the journal since the NRA to evaluate the discipline's state of scholarship and impact. It provides a 7.5-year review of research published in the JAC. Beyond that, it reveals the extent to which the published research addresses priorities and needs identified in the NRA for communications involving agriculture and related subject areas.

This study views this inventory of studies within the agricultural communications domain from the lens of social systems theory (Luhmann, 1995) and its treatment of change within a recursively-reproduced system of practice. The NRA for Agricultural Communications is seen here as a product of a coalition of actors and institutions that collaborate to gain public support and influence policy mechanisms. Hence, it is an outcome of reflexive strategic practice. As an output of a complex of actors and institutions, the NRA helps shape research and development efforts in the field, and in turn, is acted upon by other actors and institutions within and outside of the field. A regular assessment of how a discipline fares based on the content of the NRA offers opportunities 
to generate what Luhmann (1995) calls "strategic change." In this case, an assessment of the extent to which a discipline is living up to its stated research agenda could be considered an organizational "episode" in Luhmann's theory of change. It offers a mechanism by which "reflective discourses can be pursued without necessarily disrupting the practices and routines by which that system is maintained" (Hendry \& Seidl, 2003, p. 180).

Thus, an NRA represents, and is an offshoot of, sociologically observable practices and routines of a discipline. Members of the scientific community, industry, government, advocacy groups, and international institutions are involved in different ways in the development and implementation of NRAs. NRAs thus serve to organize and present the discipline to the world, in effect defining how audiences should make sense of the discipline in the constellation of other disciplines. At the same time, social-structural and/or organizational factors influence the way the members of a discipline decide on what is worthy of their research and other scientific efforts as outlined in the NRA.

Five research questions served as focus for this study:

1. What theories, methods, channels, and populations were involved in the published reports?

2. What subject matter areas received research attention during the past 7.5 years?

3. How closely do these areas of research attention match the priority areas identified in the discipline's NRA?

4. How do the findings of this study compare with those of prior analyses of research articles published in the JAC?

5. What trends, strengths, needs, and opportunities are revealed through this analysis, in terms of informing the further development of the communications research agenda for subject areas related to agriculture?

\section{Methods}

An early decision involved what national research agenda to use for this content analysis. Two related agendas have been developed during the past decade. The first was the 2007 "National Research Agenda in Agricultural Education and Communication, 2007-2010.”The second was a more integrated "National Research Agenda: American Association for Agricultural Education's Research Priority Areas for 2011-2015” released in 2011.

The earlier agenda was chosen for this content analysis because it permitted detailed analysis of research priority areas related to communications. As noted, four RPAs in the agenda included $18 \mathrm{KRQ}$ and 59 PIs. The more recent agenda provided less opportunity for detailed analysis involving communications research. It identified six national research priorities broadly encompassing agricultural education in schools, universities, and other post-secondary institutions; education and other non-formal community education and outreach programs; leadership development in individuals, communities, organizations, and agencies; and communication within and throughout the agricultural and natural resources industries.

Data for this study were gathered through a content analysis of a complete enumeration or census of articles classified by JAC as falling under the research and evaluation category published from 2008 to mid-2015. Descriptive information about these articles was considered, including the number of articles published per year, the theoretical and/or conceptual frameworks employed, the methods used, and the populations studied or sampled. These variables, their labels, operational definitions, coding protocols, and coding values were specified in the study codebook.

Research method refers to the technique used to gather data (e.g., survey, experiment, content analysis, focus group session, in-depth interview, historical analysis, case study, and other qualitative methods). Theory refers to the theoretical or conceptual framework on which a study was based. A riepress.org/jac/vol100/iss1/4 
study may stipulate more than one research method and theoretical rationale. A study also specifies a population studied or sampled (e.g., communication materials or products such as newspaper and magazine articles, radio broadcasts, extension bulletins, websites, social media messages, and policy instruments; consumers and consumer groups; agricultural communications professionals and experts; farmers and producers; media organizations; and media practitioners). A study that employed a mixed method approach may make use of multiple populations and/or samples.

Each article was coded based on the RPA under which it falls, the KRQs it asked, and the PIs addressed within each identified KRQ. Because RPAs are broad, a study may fall under multiple RPAs and respond to multiple KRQs and PIs. Thus, an article was examined to determine the presence (1) or absence (0) of all four RPAs, 18 KRQs, and 59 PIs in the NRA. Data were entered in and examined using SPSS v. 22.

To determine intercoder reliability, half of the total number of articles was selected and two journalism graduate students coded all variables after having been trained on the use of the coding scheme and protocols. Using the formula from North, Holsti, Zaninovich, and Zinnes (1963), intercoder reliability scores for the nominal variables were as follows: the theoretical and/ or conceptual framework(s) employed (97.4\%); the data gathering method(s) used (98.8\%); the population(s) studied or sampled (97.3\%); the priority area(s) under which the study falls (96.5\%); the key research question(s) asked (93.7\%); and the priority initiatives (94.8\%) the study addressed.

The unit of analysis was the complete journal article. Descriptive statistics were used to describe sample characteristics, the PRAs examined, the KRQs answered, and the PIs that were involved.

\section{Results}

\section{Research Question I}

What theories, methods, channels and populations were involved in the published reports? During those 7.5 years, the JAC published a total of 129 articles, a large majority of which fell under the research and evaluation category (108 or $83.72 \%)$. This was followed by professional development articles (10), and a sprinkling of commentaries and reviews (5 and 6, respectively). This study analyzed only those classified by the JAC itself as research articles (108 or 83.72\%). The number of such articles the journal featured grew over time, with the largest number seeing print in 2013 (22 or 20.37\%). From 2011-2014, the journal averaged 18 research articles per year, indicating a clear upward trajectory in terms of the number of peer reviewed studies published (Table 1).

Of the studies that examined the performance or characteristics of different mass media $(n=79)$, a clear majority (27 or $34.17 \%)$ analyzed the traditional print media (newspapers, magazines, other print), with the online media a close second (26 or 32.91\%). Interpersonal channels were the least explored (6 or 7.59\%). Table 1 also provides a breakdown of studies based on the channels assessed. 
Table 1

Sample Characteristics $(n=108)$

\begin{tabular}{lcc}
\hline Year of publication & $n$ & $\%$ \\
\hline 2008 & 7 & 6.48 \\
2009 & 12 & 11.11 \\
2010 & 7 & 6.48 \\
2011 & 15 & 13.88 \\
2012 & 17 & 15.74 \\
2013 & 22 & 20.37 \\
2014 & 19 & 17.59 \\
2015 & 9 & 8.33 \\
& & \\
Information channels studied $(n=79)$ & & \\
TV & 18 & 22.78 \\
Newspapers & 8 & 10.12 \\
Magazines & 11 & 13.92 \\
Other print & 8 & 10.12 \\
Online, including social networking sites & 26 & 32.91 \\
Interpersonal communication & 6 & 7.59 \\
Multimedia & 2 & 2.53 \\
\hline
\end{tabular}

Authors employed a number of theoretical and conceptual frameworks to underpin their studies. These are enumerated in Table 2. Following the trajectory of theory use in the general mass communication discipline, agricultural communications research saw a tide of studies that used framing as the theoretical rationale. This can be seen in 13 of the 94 studies (13.83\%) that specified a theoretical or conceptual framework. Some made use of the tenets of the diffusion of innovations (9 or $9.57 \%$ ) and uses and gratifications theories ( 8 or $8.51 \%$ ) as well as semiotics (7 or $7.44 \%$ ). 


\section{Table 2}

\section{Theoretical and/or Conceptual Frameworks Used ( $n=94)$}

\begin{tabular}{|c|c|c|}
\hline Theory & $n$ & $\%$ \\
\hline Framing & 13 & 13.83 \\
\hline Diffusion of innovations & 9 & 9.57 \\
\hline Uses and gratifications & 8 & 8.51 \\
\hline Semiotics & 7 & 7.44 \\
\hline Experiential learning & 5 & 5.32 \\
\hline Excellence in public relations & 4 & 4.25 \\
\hline Agenda-setting & 3 & 3.19 \\
\hline Knowledge gap & 3 & 3.19 \\
\hline Technology acceptance model & 3 & 3.19 \\
\hline Cognitive dissonance & 3 & 3.19 \\
\hline Social presence & 3 & 3.19 \\
\hline Theory of planned behavior & 2 & 2.13 \\
\hline Social cognitive theory & 2 & 2.13 \\
\hline Elaboration likelihood model & 2 & 2.13 \\
\hline Media dependency & 2 & 2.13 \\
\hline Best practices in risk communication & 2 & 2.13 \\
\hline Schema & 2 & 2.13 \\
\hline Theory of education and identity & 2 & 2.13 \\
\hline $\begin{array}{l}\text { Agricultural Knowledge and Innovation System (AKIS) } \\
\text { model (Pakistani version) }\end{array}$ & 1 & 1.06 \\
\hline Contingency theory of accommodation & 1 & 1.06 \\
\hline Editorial vigor theory & 1 & 1.06 \\
\hline Exemplification theory & 1 & 1.06 \\
\hline Expectancy value theory & 1 & 1.06 \\
\hline Functionalism & 1 & 1.06 \\
\hline Lifelong education program planning model & 1 & 1.06 \\
\hline Grounded theory & 1 & 1.06 \\
\hline Media richness theory & 1 & 1.06 \\
\hline $\begin{array}{l}\text { Memorability, efficiency, errors, learnability, and } \\
\text { satisfaction (MEELS) model }\end{array}$ & 1 & 1.06 \\
\hline Minority identity development model & 1 & 1.06 \\
\hline Model of causality in social learning & 1 & 1.06 \\
\hline Protective action decision model & 1 & 1.06 \\
\hline Social amplification of risk framework & 1 & 1.06 \\
\hline Technology integration model & 1 & 1.06 \\
\hline Theory of omniphasism & 1 & 1.06 \\
\hline Theory of social comparison processes & 1 & 1.06 \\
\hline Total food quality model & 1 & 1.06 \\
\hline Uncertainty reduction theory & 1 & 1.06 \\
\hline Articles with no specified theoretical base & 29 & 9.57 \\
\hline
\end{tabular}


Table 3 lists the array of methods applied to gather data for the compendium of studies published in the JAC. Surveys (mail, online, and telephone) topped the list with 35 of 113 methods specified (30.97\%). Because of the need to analyze media or channel performance, content analysis, the staple of communications research, was a popular method used in 28 studies $(24.78 \%)$. Focus groups (13.27\%), and in-depth interviews (11.5\%) also were frequently observed.

Table 3

Research Methods Conducted to Gather Data (n=113)

\begin{tabular}{lcc}
\hline Method 1 & $n$ & $\%$ \\
\hline Survey (mail, telephone, online) & 35 & 30.97 \\
Content analysis & 28 & 24.78 \\
Focus groups & 15 & 13.27 \\
In-depth interviews & 13 & 11.50 \\
Case study & 6 & 5.31 \\
Experiment & 5 & 4.42 \\
Delphi method & 3 & 2.65 \\
Historical analysis & 2 & 1.77 \\
Discourse analysis & 1 & 0.88 \\
Usability testing & 1 & 0.88 \\
Integrative literature review & 1 & 0.88 \\
Community forum & 1 & 0.88 \\
Non-experimental comparative design & 1 & 0.88 \\
Phenomenological analysis & 1 & 0.88 \\
\hline
\end{tabular}

The articles addressed nine broad categories of populations and samples: communications materials, which constituted 25 of the 113 identified samples (22.12\%); consumers and consumer groups, users of a particular medium, citizens or residents (17 or 15.04\%); high school and college students (16 or $14.16 \%)$; agricultural communications professionals or experts (13 or 11.5\%); farmers and producers (12 or 10.62\%); members and employees of professional and/or scientific organizations and technical experts (11 or 9.73\%); media organizations and their employees (9.73\%); developers of educational materials ( 4 or 3.53\%); and others (also 4 or 3.53\%). Table 4 shows examples of actual population groups in each category.

Communications materials were the most studied samples. In terms of channels, the findings showed a major push during the period to analyze online media content, especially the use and application of social networking sites. 
Table 4

Populations or Samples Studied ( $n=113)$

\begin{tabular}{|c|c|c|}
\hline Populations/samples studied & $n$ & $\%$ \\
\hline $\begin{array}{l}\text { Communication materials (advertising pieces, photos, } \\
\text { photo-illustrations, logos, newspaper articles, TV } \\
\text { transcripts, Tweets, journal articles, books, websites, } \\
\text { comments, blogs, policy pieces, campaign materials, } \\
\text { films) }\end{array}$ & 25 & 22.12 \\
\hline $\begin{array}{l}\text { Consumers and consumer groups, users of a particular } \\
\text { medium, citizens, residents }\end{array}$ & 17 & 15.04 \\
\hline Students, college and high school & 16 & 14.16 \\
\hline $\begin{array}{l}\text { Agricultural communication professionals and experts } \\
\text { (editors, blog authors, faculty, publishers, Facebook } \\
\text { group administrators of ag organizations, alumni, } \\
\text { public relations practitioners, campaigners, teachers) }\end{array}$ & 13 & 11.50 \\
\hline $\begin{array}{l}\text { Farmers (ranchers, dairy producers, beef producers, } \\
\text { grain growers, citrus growers, managers of beeflots, } \\
\text { alternative agriculture producers, coffee growers, } \\
\text { agriculturalists, agricultural producers) }\end{array}$ & 12 & 10.62 \\
\hline $\begin{array}{l}\text { Members and employees of professional and/or scientific } \\
\text { organizations, technical experts (agritourism } \\
\text { operators, horticulturists, ag marketers) }\end{array}$ & 11 & 9.73 \\
\hline $\begin{array}{l}\text { Media organizations and members and employees of } \\
\text { media organizations (news directors and reporters, } \\
\text { TV reporters, editors, ag journalists) }\end{array}$ & 11 & 9.73 \\
\hline $\begin{array}{l}\text { Educational materials (course, curricula, course packets, } \\
\text { degree programs, disciplinary organizations) }\end{array}$ & 4 & 3.53 \\
\hline $\begin{array}{l}\text { Other (shareholders, stakeholders, general crisis response, } \\
\text { government officials) }\end{array}$ & 4 & 3.53 \\
\hline
\end{tabular}

\section{Research Question 2}

What subject matter areas received research attention during the past 7.5 years?

Each research article was coded with respect to the RPA, the key research questions under each RPA, and the priority initiatives under each KRQ as specified in the agenda. Table 5 summarizes the frequency counts for each item across all levels. It shows that RPA A, "Enhance decision making within the agricultural sectors of society," received the most attention from scholars. It was evident in 89 of the 108 research articles analyzed (82.40\%). Within this RPA, the most commonly asked question was, "What are the most effective ways to identify and communicate information that has economic and social value?" which was detected in 47 articles. Of the published articles within this KRQ,21 analyzed the effectiveness of communications content and methods. Many (25 articles) provided answers to the KRQ, "Who are the relevant audiences with respect to high priority issues?" Subsumed under this research question, 13 articles examined the information needs and preferences of identified audiences. 


\section{Table 5}

Priority Research Areas, Key Research Questions and Priority Initiatives Addressed in the JAC, 2008 to mid-2015 (n=108)

Priority

Research Areas/

Key Research

Priority Initiatives

$n$

Questions

\section{A. Enhance decision making within agricultural sectors}

1. Who are the relevant audiences with respect to bigh priority issues?

a. Develop and improve tools for audience identification and communication analysis

b. Determine information needs and preferences of identified audiences

c. Determine information sources and factors that influence perceptions of audience trust and credibility

2. What are the most effective ways to identify and communicate information that has economic and social value?

a. Analyze roles, use, and effectiveness of information structures, systems and concepts b. Analyze and strengthen the effectiveness of communications content and methods

b. Analyze and strengthen the effectiveness of communications content and methods

c. Analyze and strengthen the effectiveness of information technologies

d. Strengthen guidelines for using planned, coordinated approaches for agricultural decision making

e. Examine economic returns to, and social impacts of, ag information in various forms, settings, and audiences

f. Develop, identify, test, and evaluate the most viable tools for assessing the economic value of ag information

g. Develop approaches for enhancing decision making by systematically engaging key interest groups

h. Adapt and test models of collaboration, mediation, negotiation, conflict management, and joint problem solving for decision making

i. Determine critical success factors in ag knowledge management systems, networks, and processes

3. What information do stakeholders need to make informed decisions?

a. Assess the impact of information on informed decision making

b. Develop guidelines for providing information that balances perspectives of change and stability in agriculture 
Priority

Research Areas/

Key Research

Priority Initiatives

$n$

Questions

c. Analyze past and current patterns of conflict

avoidance and resolution in the ag/food

complex

d. Use normative inquiry in analyzing ag-related

communications systems, programs and methods

e. Evaluate the ability of messages and channels to change behavior

f. Use critical theory in analyzing ag-

related communication systems,

programs and methods, domestically and

internationally

g. Examine and strengthen ethical dimensions

of knowledge management systems and processes

h. Analyze activities associated with knowledge management and their use within various stakeholder groups

i. Identify best practices and potential barriers and test models for recording and disseminating tacit and explicit knowledge

j. Understand the interplay between data, information and meaning within various groups of ag stakeholders

\section{B. Rural-urban interactions: Within and among societies, aid the public in participating in public decision making related to agriculture}

1. How do we reach, create awareness, and constructively engage high-priority agricultural issues?

a. Develop and test guidelines for building coalitions for public decision making

b. Adapt and develop models of collaboration, mediation, and conflict management to advance ag decision making

c. Examine the extent, forms, outcomes, and effectiveness of public participation regarding agrelated decision making

d. Analyze the communications aspects of current and emerging social movements

e. Explore the interface of ag science and communication, including the ways by which communications institutions, systems, and methods are used to shape identities, perceptions, and social outcomes

2. How do we identify, assimilate, disseminate, format, and evaluate information that facilitates decision making about high-priority ag issues?

a. Examine and assess the quality and adequacy of information available for local, national, and international public decision making related to highpriority ag issues, current and past 
Priority

Research Areas/

Key Research

Priority Initiatives

$n$

Questions

b. Understand how the public interprets, creates meaning, and values information related to high-priority ag issues

c. Identify information asymmetries, barriers, and imperfections in public participation in the decision making process

3. How do we improve the effectiveness of mass and other mediated coverage of ag issues?

a. Develop ways to monitor the rural-urban interface continuously to anticipate social issues that involve ag and proactively engage the mass media in covering them

b. Examine the amount and effectiveness of media coverage of ag-related topics, current and past

c. Improve strategies to strengthen media coverage of ag-related issues

d. Test in-service training methods for helping media professionals improve their skills in covering agriculture

4. How will emerging technologies impact the flow of ag-related information in support of public participation?

a. Identify, adapt, and test new, emerging, and changing information technologies for ag knowledge management

b. Use communication theory to improve the application of media in engaging the public in ag decision making

\section{Build societal knowledge and intellectual capabilities}

1. How do we improve thinking processes and problem solving capabilities through information systems?

a. Identify and analyze the drivers of local, national, and international cultural change within public agencies, organizations, and media institutions to guide the improvement of ag information systems

b. Monitor knowledge transfer systems and knowledge flows and develop ways to improve effectiveness

2. How does information delivery affect thinking processes, problem solving, and decision making?

a. Examine the role and effectiveness of information in ag-related decision making of individuals, groups, and societies

b. Analyze how professional communicators gather, process, and use information to plan approaches to communications 
Priority

Research Areas/

Key Research

Priority Initiatives

Questions

3. How can we gather and make available the widely scattered literature about ag-related communications internationally?

a. Analyze and seek ways to strengthen the efforts of the Agricultural Communications Documentation Center and other mechanisms to identify and process such literature and to make it more widely and readily available

b. Develop ways to capture and share expert knowledge related to ag

4. How do we use communications networks, linkages, and approaches more effectively in ag knowledge management?

a. Experiment with knowledge management tools and other exchange mechanisms to strengthen decision making

b. Examine ways to identify existing professional ag communication organizations globally and foster linkages among them

5. What sectors of society contain our most valuable ideas and knowledge?

a. Determine how the sharing of knowledge among sectors of society can be supported

b. Examine if and how knowledge gains value when being shared with others

6. What strategies can we apply to prepare organizations for shifts in ag knowledge management?

a. Examine common and unique characteristics of ag knowledge markets and knowledge communities and their impact on knowledge management strategies

7. How do we weave ideas of knowledge and its value into ag and remain able to function in the present business situation?

a. Examine how Knowledge Age factors (e.g., 24/7 business hours) impact the ag complex

8. How do we balance the needs, wants, and aspirations of individuals with those of larger organizational structures related to ag?

a. Determine the ethical standards for the fair exchange of knowledge and information within an economy

b. Examine the functional and organizational changes in knowledge management among ag entrepreneurs 
Priority

Research Areas/

Key Research

Priority Initiatives

Questions

\section{Develop effective agricultural workforces for knowledge-based} societies

1. What are the theoretical underpinnings of and synergistic relationships between knowledge management and ag communications as a field of research, education and practice?

a. Analyze features and potentials of knowledge management concepts and technologies as an integrative framework for ag communications research

b. Examine the theoretical base for agricultural communications research, including connections between it and related disciplines

2. What are the skills and competencies needed to improve the communications and knowledge management effectiveness in the ag workforces?

a. Develop strategies and mechanisms to strengthen the communication skills and perspective of ag professionals

b. Develop strategies and mechanisms to increase the critical thinking skills of ag professionals

3. What are the skills, competencies, and resources needed to prepare professional ag communicators for success?

a. Identify and analyze the communications skills and perspectives necessary within the diverse career sectors in which professional ag communicators work now and in the future

b. Provide insights to strengthen courses, curricula, and other aspects of ag communications and related academic programs

c. Develop and enhance mechanisms to strengthen the knowledge base for ag communicators and provide career-long professional learning opportunities for them

d. Identify guidelines for strengthening the international and cross-cultural perspectives and skills of ag communicators

e. Develop and test methods for increasing the critical thinking skills of professional ag communicators

Note: Percentages do not add to $100 \%$ because an article may respond to multiple PRAs, KRQs and PIs. 
RPA B, "Within and among societies, aid the public in effectively participating in public decision making related to agriculture," was the subject of 63 research articles (58.33\%). Articles that exhibited this RPA generally asked, "How do we improve the effectiveness of mass and other mediated coverage of agricultural issues?" (25 articles) and "How will emerging technologies impact the flow of information in support of public participation?" (18 articles). These two KRQs are the subject of studies that intended to quantify the extent and effectiveness of media coverage of agriculture-related issues. These KRQs also circumscribe articles that examined the thoroughness, accuracy, and overall quality of media coverage.

The fourth RPA (RPA D), "Develop effective agricultural workforces for knowledgebased societies," was the subject of 43 articles (39.81\%). Of the articles that discussed this RPA, 26 addressed the question, "What are the skills, competencies and resources needed to prepare professional agricultural communicators for success in various aspects of agricultural knowledge management?" Most of these articles provided insights to strengthen courses, curricula, and other aspects of academic programs, and analyzed the communications skills and perspectives necessary within the diverse career sectors in which professional agricultural communicators work currently and are expected to participate in the future.

The area least studied is RPA C, "Build competitive societal knowledge and intellectual capabilities." Only 36 articles (33.33\%) addressed it. Under this broad area, many studies (20) generally asked, "How does information and media delivery affect thinking processes, problem solving and decision making related to agriculture?" Fifteen of the articles that focused on this question looked at the role and effectiveness of information in the decision making of individuals, groups, and societies.

\section{Research Question 3}

How closely do these areas of research attention match the priority areas identified in the discipline's national research agenda?

Based on frequency counts, $16.7 \%$ of the key research questions and $43.9 \%$ of the priority initiatives remained unaddressed or largely so during this period.

Under the first research priority area (RPA A), for example, no study examined the economic returns to, and social impacts of, agricultural information in various forms, settings and audiences. Largely missing were inquiries that attempted to develop approaches to enhance agricultural decision making by systematically engaging key interest groups, and those that develop and test tools that assess the value of ag information. Research during the period also lacked attention to adapting and testing models of collaboration, mediation, negotiation, conflict management, and joint problem solving for decision-making endeavors beyond confrontational approaches. Little research during the period assessed the critical success factors in agricultural knowledge management systems, networks, and processes. All of these priority initiatives fall under the second KRQ of the first research priority area.

Also within the first RPA, some priority initiatives under KRQ 3 received little attention. In particular, few studies aimed at developing guidelines for providing information that balances perspectives of change and stability. Rarely did the studies analyze past and current patterns of conflict avoidance and resolution. Few used normative and critical inquiry to analyze communications systems, programs and methods, locally and abroad. Moreover, little was reported during the period about the findings of studies that assessed the historical and ethical dimensions of agricultural knowledge management systems and processes, and efforts to understand the interplay among data, information, and meaning within various groups of stakeholders.

Under RPA B, there was a dearth of studies with the objective of developing and testing guidelines for building coalitions for public decision making, adapting and developing models of conflict management to advance agricultural decision making efforts beyond conflict-based 
approaches, and examining the extent, forms, outcomes and effectiveness of public participation in decision making processes. Gaps also appeared in efforts to explore the interface of agricultural science and communication, including specific ways in which communications institutions, systems, and methods are used to shape identities, perceptions, and social outcomes. Research gaps also pointed to the need to identify information asymmetries, barriers, and imperfections in public participation in the decision making process on high-priority rural-urban issues. Also observed is the paucity of studies that test in-service training methods for helping mass media professionals improve their skills in covering agriculture.

Articles published under RPA C revealed gaps in all but three KRQs. Studies that attempted to provide answers to questions pertaining to how to make available the widely scattered literature about agriculture-related communications internationally were few and far between. Within the third RPA, two other KRQs remained under-studied: How can agricultural communicators weave the ideas of knowledge and its value into agriculture and remain able to function in the present business situation? How do strategists balance the needs, wants, and aspirations of individuals with those of larger organizational structures related to agriculture?

Within RPA D, studies that devoted energies on mechanisms to strengthen the knowledge base of ag communicators and providing them with professional learning opportunities were scant. Only two articles responded to the priority initiative of developing guidelines to strengthen the international and cross-cultural perspectives and skills of professional communicators in agriculture.

\section{Research Question 4}

How do the findings of this study compare with those of prior analyses of research articles published in the JAC?

Efforts to compare results of this study with those from two previous analyses of JAC articles (Williams \& Woods, 2002, covering 1992-2001; and Edgar, Rutherford \& Briers, 2009, covering 1997-2006) proved useful, if limited to three shared dimensions. All three studies reported the number of articles produced across specific time periods. All reported the research methods employed, revealing more use of quantitative than qualitative methods and led by surveys, content analyses, case studies, interviews, and evaluations. Researchers uniformly called for more variety in research methods.

The three analyses varied considerably in categorizing research topics. The current study, involving the agricultural communications NRA, used an integrated systems and knowledge management framework, was broad in scope, focused on social or professional impact, and was largely independent of specific skills, activities, or issues. The two earlier analyses featured topics that were less inter-connected and more specific, led in frequency by articles about information sources and technologies, electronic media, communications management, media relations, biotechnology communications, and professional development. Writing, photography, graphic design, audience analysis, distance education, globalization, and issue framing were among other topical categories in those analyses.

\section{Research Question 5}

What trends, strengths, needs, and opportunities are revealed through this analysis, in terms of informing the further development of the communications research agenda for the subject areas related to agriculture?

The past 7.5 years of communications research reported in JAC reveal meaningful trends. The number of research articles published per year showed growth, with 2013-2014 serving as watershed years. The survey (mail, telephone or online) dominated as the method used, but evidence suggests a broadening menu of quantitative and qualitative research methods. Framing riepress.org/jac/vol100/iss1/4 
theory was the most employed theoretical basis, although a wide range of theories and conceptual frameworks were applied to anchor empirical studies. The range of theoretical frameworks shown in Table 2 suggests a discipline that has come to recognize the value of contributing to the body of knowledge in the broader field of communications by testing formal frameworks in agriculture and related domains.

\section{Discussion and Recommendations}

The findings identified needs and opportunities for added research about dozens of topics for enhancing decision making within agriculture and among stakeholders in public decisions related to agriculture. Such research is critical, especially as the discipline grapples with increasingly contentious issues that need to be negotiated and managed within agriculture, and beyond.

This study also revealed significant need and opportunity for research about other priority initiatives such as: economic returns to, and social impacts of, agricultural information; how to systematically engage key interest groups; models of collaboration, negotiation, and conflict management; the use of critical theory in analyzing communication systems; the historical and ethical dimensions of agricultural knowledge management systems; ways of helping media professionals improve their skills in covering agriculture; how to make literature more widely and readily available; how knowledge gains value when shared; and the functional and organizational changes in knowledge management among agricultural entrepreneurs and corporations.

In short, the diverse themes, theories, and methods evident in research articles published in the JAC during this recent 7.5-year period suggest that agriculture-related communications research is coming of age. It is addressing new branches of inquiry. The battery of research articles examined indicates attention to heretofore untouched research themes, such as deciphering best practices before, during, and after crisis and risk situations (Veil and Sellnow, 2008; White and Rutherford, 2008; Ashlock, Cartmell \& Leising, 2009) particularly when food safety is under threat (Irlbeck, Akers \& Palmer, 2011; Barr, Irlbeck \& Akers, 2012; Irlbeck, Jennings, Meyers, Gibson \& Chambers, 2013), incidences of agroterrorism (Ashlock, Cartmell \& Leising, 2009 and 2012; Riley, Cartmell \& Naile, 2012) and plant and animal disease outbreaks (e.g., Cannon and Irani, 2011; Narayana, 2013); the impact of the popular and entertainment media on cognitions and attitudes (e.g., Meyers, Irlbeck \& Fletcher, 2011; Holt \& Cartmell, 2013; Specht \& Rutherford, 2015); people's perceptions of agricultural terminologies, sources, and issues (Goodwin, Chiarelli \& Irani, 2011; Barr, Irlbeck, Meyers \& Chambers, 2011; Rumble, Holt \& Irani, 2014); the role of communication in ag policy formulation (e.g., Goodwin \& Rhoades, 2011); the use of emerging and new media to communicate issues (e.g., Wagler \& Cannon, 2009; Moore, Meyers, Irlbeck \& Burris, 2009; Meyers, Irlbeck, Graybill-Leonard \& Doerfert, 2011; Baker \& Irani, 2014) and to foment social movements (Graybill-Leonard, Meyers, Doerfert \& Irlbeck, 2011); communication strategies to reach audiences with disabilities (Christen \& Fetsch, 2008); the role of communication in emerging industries within agriculture (Miller, McCullough, Rainey \& Das, 2012); and the impact of organizational brand salience and differentiation (Settle, Goodwin, Telg, Irani, Carter \& Wysocki, 2012; Settle, Baker \& Irani, 2014), to name a few of the most obvious recent branches of inquiry.

\section{Diversifying the Inquiry}

A synthesis of research topics suggests two research aspects that would clearly benefit from continued diversification. The first is in the conceptualization of agricultural communications itself. Historically rooted in production agriculture, it has become a complex construct involving not only farming/ranching and food production, rural affairs, natural resources, and the environment, but also the issues involved when science and society interact, such as risk and uncertainty, expertise or perceptions thereof, and the public's agriculture and science literacy. This multifaceted conceptualization demands attention to new and emerging areas of application. Indeed, the 
framework of the NRA offers encouragement and directions for doing so. The blossoming of newer areas of research within this very broad domain, such as the use of new and emerging media to reach out to more diverse populations and the popularization of agricultural science themes, is a promising trend.

The second aspect that would benefit from diversification is the inquiry itself. This refers to data gathering methods beyond surveys, focus groups, in-depth interviews, and content analyses, to include attempts to uncover long-term audience effects through longitudinal designs, stronger measures of causality through experiments, and analytical (as opposed to descriptive) surveys that provide evidence for relationships between and among variables. Within the body of research analyzed, the sharp focus was on communications content, but very little emphasis was placed on the downstream effects of content on audiences or the upstream organizational or social factors that lead to such content.

\section{Advancing the Research Agenda}

Broad commitments of societies to the scientific and technological enterprise and the attendant value of research in the discipline point to seven considerations and future directions scholars could take to advance the relevance and responsiveness of agriculture-related communications to societal needs. They are as follow:

\section{Studies that attempt to understand the impact of communications on audiences demand greater} attention. Audience effects studies are few and far between and the impacts of communication are often inferred and rarely tested. More audience-oriented questions are in order, considering consumers' need for information and the decisions they make about what sources of information to use given the expanding array of possibilities. What kinds of information do people want and to what extent do they satisfy their information needs? Does being exposed to content increase or decrease people's perceived susceptibility to risk, and if so, do those changes in perceived susceptibility influence adoption of preventive behaviors? Or does the coverage simply remind people of their greatest fears, leading to fear control responses that may ultimately put them at greater risk? These questions are critical, considering changing consumption patterns, information delivery systems, and increased fragmentation of audiences brought about by advances in communication technology.

\section{Content analysis findings should lead to questions that examine why agriculture and related} topics are presented the way they are. This line of inquiry calls for an examination of journalistic routines and practices to answer questions such as: Why do editors make the choices they make about which topics do and do not receive coverage? Have there been drastic changes to conventional gatekeeping processes? Why are some information items emphasized more often than others? What motivates information gatekeepers to include and exclude various kinds of information? Such studies also could examine the influence of other factors in the creation or modification of content, including cultural, social-structural or organizational variables, the ideological leanings of sources and content producers, or perceived audience demand and need for specific kinds of information.

3. More attention to the visual. One obvious difference between the online media and other channels is in the predominance of visuals over text. Surprisingly, only a handful of the examined studies considered visuals as carriers of relevant meaning (e.g., Glaze, Edgar, Rhoades \& Rutherford, 2013; Specht and Rutherford, 2013; Borron, 2013). Yet visuals are known to be easier to comprehend and lead to different audience effects than text. Overlooking the influence of visuals may be handicapping critical insights to what agriculture-related communication products are contributing. As a corollary, audience studies could examine if the activity of the audience intersects with either the expectation for certain kinds of content or the effects of it. Comparative studies contrasting the coverage of agriculture and related issues or its effects between other forms

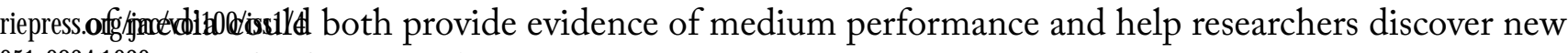


4. Take framing studies to new directions. The array of studies that examined how specific topics or issues have been framed or portrayed (e.g., Meyers and Abrams, 2010; Irlbeck, Akers \& Palmer, 2011; Abrams and Meyers, 2012) points to new directions for framing research. Studies that employed frame analysis primarily detected the presence (or absence) of discrete information items. Further analyses can address how a topic has been discursively presented or contextualized to purposively influence audience beliefs, attitudes, and practices. Popular discourse about agriculture and related issues will be expanded profitably by considering a broader array of meta-perspectives or holistic frames. Furthermore, of the 13 framing studies analyzed, a great majority limited the scope to the analysis of content or media frames. Future efforts could delve into how audiences interpret media frames and whether the differences in tone of coverage across issues affected people's behavior, knowledge, and attitudes.

5. Apply theories from science and risk communications. While framing can be applied to most topics and media, other theories and conceptual frameworks could be employed to better understand agriculture and related issues as they are conveyed through communications. These areas generally address the interaction of science within society and include topics such as risk communications, presentation of uncertainty, perceptions of trust, expertise and credibility, and dimensions of agriculture literacy.

Taking risk communication as an example, many theories attempt to explain how individuals come to form judgments when presented with risk information, using factors such as information insufficiency, fear, or cultural worldviews. Studies could apply any of these theories to, for instance, predict or explain the response of readers to specific types of coverage. The benefit of such theoretical application is that results can be generalized beyond specific issues and can provide predictive power in new contexts.

6. Adopt a more international and intercultural lens. Studies that display international and intercultural perspectives appeared rarely in JAC during this period. Only five studies did so (Cai and Abbott, 2013; Kubitz, Telg, Irani \& Roberts, 2013; Narayana, 2013; Ezezika \& Mabeya, 2014; and Cannon \&Irani, 2011). The low performance in this research area is troubling given the demands for global food security exacerbated by climate change threats. Emphasizing intercultural and international dimensions supports the development of globally-engaged and culture-sensitive communicators.

\section{Maintain an agricultural communications research agenda, collaborating within journalism/} communications and other agriculture-related social and human sciences. Results of this study underscore the value of a research agenda that focuses specifically on communications related to the broad domains of agriculture, natural resources, and life and human sciences. Insights reported here would not be possible without one. It reflects several key features of Turnbull's (1979) "priority convergence technique" which systematically involves all parties with informed interest in the research agenda, allows those parties to define and communicate their own priorities, provides for cross-group communications, allows for a convergence or synthesis across priority sets, and thus helps create a unified effort. Use of this framework for an agricultural communications research agenda also permits unlimited refinements, over time, in topic priorities and other dimensions (Doerfert et al., 2007, p. 18).

Beyond these seven considerations, an important follow-up research effort should delve into meta-analysis, which contrasts and combines the results of multiple studies dealing with a similar phenomenon. Such analysis can help identify patterns among results, sources of disagreement among those results, or other meaningful relationships that may come to light in the context of multiple studies. It can help synthesize the results of existing empirical studies to develop generalizations about significant research domains.

In summary, the national research agenda for communications related to agriculture, natural resources, and life and human sciences is proving insightful and promisingly valuable for advancement in this discipline. The Journal of Applied Communications serves an expanding, vital role in reporting the results of that agenda. 


\section{References}

Abrams, K., \& Meyers, C. (2012). From opposite corners: Comparing persuasive message factors and frames in opposing organizations' websites. Journal of Applied Communications, 96(1), 54-67.

Ashlock, M. S., Cartmell, D. D., \& Leising, J. G. (2009). Before it hits the fan: Pre-crisis beef producer information source preferences. Journal of Applied Communications, 93(3\&4), 2-43.

Ashlock, M. A., Cartmell, D., \& Leising, J. G. (2012). Beef producers' risk perceptions of an agroterrorism event occurring in Oklahoma. Journal of Applied Communications, 96(3), 6573.

Association for Communication Excellence in Agriculture, Natural Resources, and Life and Human Sciences [ACE]. (n.d.). Retrieved from http://www.aceweb.org

Baker, L. M., \& Irani, T. (2014). The impact of new media on policy affecting agriculture. Journal of Applied Communications, 98(3), 17 -31.

Barr, K., Irlbeck, E., Meyers, C., \& Chambers, T. (2011). Television journalists' perceptions of agricultural stories and sources in Texas. Journal of Applied Communications, 95(3), 57-67.

Barr, K., Irlbeck, E., \& Akers, C. (2012). Salmonella and the media: A comparative analysis of coverage of the 2008 salmonella outbreak in jalapeños and the 2009 salmonella outbreak in peanut products. Journal of Applied Communications, 96(1), 29-41.

Borron, A. (2013). Picturing the underserved audience: Photovoice as method in applied communication research. Journal of Applied Communications, 97(4), 6-18.

Cai, T., \& Abbott, E. (2013). Using video as a replacement or complement for the traditional lecture/demonstration method in agricultural training in rural Uganda. Journal of Applied Communications, 97(4), 47-61.

Cannon, K. J., \& Irani, T. (2011). Fear and loathing in Britain: A framing analysis of news coverage during the foot and mouth disease outbreaks in the United Kingdom. Journal of Applied Communications, 95(1), 6-21.

Carnahan, W. E. (2000). A brief history of ACE. Journal of Applied Communications, 84(3), 7-19.

Christen, C. T., \& Fetsch, R. J. (2008). Colorado AgrAbility: Enhancing the effectiveness of outreach efforts targeting farmers and ranchers with disabilities. Journal of Applied Communications, 92(1\&2): 57f-73.

Doerfert, D. L. (Ed.) (2011). National research agenda: American Association for Agricultural Education's research priority areas for 2011-2015. Lubbock, TX: Texas Tech University, Department of Agricultural Education and Communications.

Doerfert, D. L., Evans, J., Cartmell, D., \& Irani, T. (2007). Developing an international framework and agenda for agricultural communications research. Journal of Applied Communications, 91(3-4), 7-21.

Edgar, L., Rutherford, D., \& Briers, G. (2009). Research themes, authors, and methodologies of the Journal of Applied Communications: A ten-year overview. Journal of Applied Communications, 93(1\&2), 21-31.

Ezezika, O., \& Mabeya, J. (2014). Improving communication in agbiotech projects: Moving toward a trust-centered paradigm. Journal of Applied Communications, 98(1), 38-44.

Glaze, C., Edgar, L. D., Rhoades-Buck, E., \& Rutherford, T. (2013). Visual communications: An analysis of university students' perceptions of rural America based on select photographs. Journal of Applied Communications, 97(1). 9-24.

Goodwin, J. N., Chiarelli, C., \& Irani, T. (2011). Is perception reality? Improving agricultural messages by discovering how consumers perceive messages. Journal of Applied Communications, 95(3), 22-33.

Goodwin, J., \& Rhoades-Buck, E. (2011). Agricultural legislation: The presence of California riepress.org/jac/volPoblisssidsition 2 on YouTube. Journal of Applied Communication, 95(1), 22-35. 
Graybill-Leonard, M., Meyers, C., Doerfert, D., \& Irlbeck, E. (2011). Using Facebook as a communication tool in agricultural-related social movements. Journal of Applied Communications, 95(3), 45-56.

Hendry, J., \& Seidl, D. (2003). The structure and significance of strategic episodes: Social systems theory and the routine practices of strategic change. Journal of Management Studies, 4O(1), 175-196.

Holt, J., \& Cartmell, D. (2013). Consumer perceptions of the U.S. agriculture industry before and after watching the film Food, Inc. Journal of Applied Communications, 97(3), 45-56.

Irlbeck, E. G., Akers, C., \& Palmer, A. (2011). A nutty study: A framing analysis of the 2009 salmonella outbreak in peanut products. Journal of Applied Communications, 95(2), 48-59.

Irlbeck, E., Jennings, J. F., Meyers, C., Gibson, C., \& Chambers, T. (2013). A case study of the crisis communications used in the 2009 salmonella outbreak in peanut products. Journal of Applied Communications, 97(4), 20-32.

Journal of Applied Communications. (n.d.). Publication guidelines. Retrieved from http:// journalofappliedcommunications.org/publication-guidelines.html

Kubitz, L., Telg, R., Irani, T., \& Roberts, O. (2013). Perceptions of global and domestic agricultural issues held by international agricultural journalists. Journal of Applied Communications, 97(4), 77-95.

Luhmann, N. (1995). Social systems. Stanford, CA: Stanford University Press.

Meyers, C., \& Abrams, K. (2010). Feeding the debate: A qualitative framing analysis of organic food news media coverage. Journal of Applied Communications, 94(3\&4), 22-36.

Meyers, C., Irlbeck, E., \& Fletcher, K. (2011). Post secondary students' reactions to agricultural documentaries: A qualitative analysis. Journal of Applied Communications, 95(3), 82-95.

Meyers, C., Irlbeck, E., Graybill-Leonard, M., \& Doerfert, D. (2011). Advocacy in agricultural social movements: Exploring Facebook as a public relations communication tool. Journal of Applied Communications, 95(3), 68-81.

Miller, J., McCullough, S., Rainey, D., \& Das, B. (2012). Communication training needs in Arkansas' agritourism industry. Journal of Applied Communications, 96(1), 68-81.

Moore, M., Myers, C., Irlbeck, E., \& Burris, S. (2009). U.S. agricultural commodity organizations' use of blogs as a communications tool. Journal of Applied Communications, 99(2), 61-75.

Naile, T., Robertson, T., \& Cartmell, D. (2010). Examining JAC: An analysis of the scholarly progression of the Journal of Applied Communications. Journal of Applied Communications, 94(1\&2), 49-60.

Narayana, M. R. (2013). Management of coffee leaf rust disease in India: Evidence for channels of communication. Journal of Applied Communications, 97(3), 71-83.

North, R. C., Holsti, O. R., Zaninovich, M. G., \& Zinnes, D. A. (1963). Content analysis: A handbook with applications for the study of international crisis. Evanston, IL: Northwestern University Press.

Osborne, E. (n.d.). National research agenda-Agricultural education and communication research priority areas and initiatives, 2007-2010. A joint project of the American Association for Agricultural Education, Association for Communication Excellence, Association for International Agricultural and Extension Education, Association of Leadership Education, NCAC-24 of the Experiment Station Committee on Organization and Policy, and National Council for Agricultural Education. 24 pp.

Osborne, E. (2007). A note from the Project Coordinator. In AAAE, ACE, AIAEE, ALE, NCAC-24, Experiment Station Committee on Organization and Policy, and the National Council for Agricultural Education, National Research Agenda: Agricultural Education and Communication, 2007-2010. Retrieved from https://www.ageds.iastate.edu/sites/default/ files/page/files/National\%20Reserach\%20Agenda\%20for\%20Ag\%20Ed\%202007-2010.pdf 
Riley, K., Cartmell, D., \& Naile, T. (2012). Kansas beef feedlot managers' trusted sources of information concerning an agroterrorism event. Journal of Applied Communications, 96(2), 39-49.

Rumble, J. N., Holt, J., \& Irani, T. (2014). The power of words: Exploring consumers' perceptions of words commonly associated with agriculture. Journal of Applied Communications, 98(2), 2336.

Settle, Q., Goodwin, J., Telg, R., Irani, T., Carter, H., \& Wysocki, A. (2012). Brand salience and brand differentiation of the Florida Forest Service. Journal of Applied Communications, 96(3), 11-25.

Specht, A. R., \& Rutherford, T. (2013). Agriculture at eleven: Visual rhetoric and news media portrayals of agriculture. Journal of Applied Communications, 97(4), 96-106.

Specht, A. R., \& Rutherford, T. (2015). The pastoral fantasy on the silver screen: The influence of film on American cultural memory of the agrarian landscape. Journal of Applied Communications, 99(1), 22-37.

Settle, Q., Baker, L. M., \& Irani, T. (2014). Employee perceptions of the brand salience and differentiation for a state forestry organization. Journal of Applied Communications, 98(1), 25-37.

Turnbull, W. W. (1979). Setting agendas for social research. Educational Researcher, 8(8), 9-12, 24.

U.S. Interagency Council on Homelessness. (2012). National research agenda: Priorities for advancing our understanding of homelessness. Retrieved from http://usich.gov/resources/uploads/asset_ library/ResearchAgendaFINAL_10-25-12.pdf

Veil, S. R., \& Sellnow, T. L. (2008). Organizational learning in a high-risk environment: Responding to an anthrax outbreak. Journal of Applied Communications, 92(1\& 2), 75-93.

Wagler, A., \& Cannon, K. J. (2009). Exploring ways social media data inform public issues communication: An analysis of Twitter conversations during the 2012-2013 drought in Nebraska. Journal of Applied Communications, 99(2), 45-75.

White, J. M., \& Rutherford, T. (2008). Impact of reporter work role identity on news story source selection: Implications for coverage of agricultural crises. Journal of Applied Communications, 93(3\&4), 15-31.

Williams, R. A., \& Woods, M. D. (2002, August). A synthesis of agricultural communication research published in the Journal of Applied Communications from 1992-2001. Paper presented at the Agricultural Communicators in Education International Conference, Savannah, GA.

\section{About the Authors}

Dr. Rodriguez is director of the Agricultural Communications Program at the University of Illinois. Her research at the intersection of science and risk communication includes media performance in communicating science and risk, and the design and evaluation of communication campaigns and strategies to extend research results to farmers, rural communities, policy makers, and the general public.

Dr. Evans is an emeritus professor in agricultural communications at the University of Illinois. He helped develop the Agricultural Communications Program, beginning in 1962, and served as head of the Office of Agricultural Communications and Education for 10 years prior to retirement. He took part in developing the National Research Agenda in Agricultural Communications in 2005-2006. 